\title{
Transtornos Mentais Graves na Atenção Básica: Experiências de Profissionais de Equipes da Saúde da Família
}

\author{
Severe Mental Disorders in Primary Health Care: Experiences of Professionals from \\ Family Health Teams
}

\section{Trastornos Mentales Graves en Atención Primaria: Experiencias de Profesionales de Equipos de Salud Familiar}

\author{
Carlos de Sousa Filho \\ Faculdade de São Lourenço (UNISEPE) \\ João Leite Ferreira Neto \\ Pontifícia Universidade Católica de Minas Gerais (PUC Minas)
}

\begin{abstract}
Resumo
Este estudo visou conhecer a experiência das equipes de saúde da família junto a usuários com transtornos mentais severos e persistentes, a partir dos sentidos atribuídos à clientela com transtornos mentais, bem como das práticas desenvolvidas pelos profissionais. Para tanto, realizouse uma pesquisa de campo, qualitativa e descritiva, na qual foram entrevistados oito profissionais de Unidades de Saúde da Família, sendo uma urbana e uma rural. Os dados foram analisados a partir da perspectiva da análise de conteúdo. Nos resultados, evidenciou-se o medo de alguns participantes em relação às pessoas com transtornos mentais, uma tentativa dos profissionais de reconhecer estas pessoas a partir de um sentido. No manejo, observaram-se procedimentos como a coleta da história de vida, a visita domiciliar e a dificuldade de a família participar do tratamento. Enfim, identificou-se a necessidade de trabalhar com as equipes conhecimentos sobre os transtornos mentais, o vínculo e a Atenção Básica.
\end{abstract}

Palavras-chave: atenção primária à saúde, transtornos mentais, equipes de saúde da família

\begin{abstract}
This study aimed to know the experience of family health teams with users with severe and persistent mental disorders, based on the meanings attributed to users with mental disorders, as well as the practices developed by professionals. Therefore, qualitative and descriptive field research was carried out, in which eight professionals from Family Health Units were interviewed, one urban and one rural. We analyzed the data from the perspective of content analysis. In the results, the fear of some participants concerning people with mental disorders was evidenced, an attempt by professionals to recognize these people from a meaning. In management, procedures were observed, such as the collection of life history, home visits, and the family's difficulty in participating in the treatment. Finally, it was identified the need to work with the teams on knowledge about mental disorders, the bond, and Primary Care.
\end{abstract}

Keywords: primary health care, mental disorders, patient care team

\section{Resumen}

Este estudio buscó conocer la experiencia de los equipos de salud familiar con usuarios con trastornos mentales graves y persistentes. Para ello, se realizó una investigación de campo cualitativa y descriptiva, en la que se entrevistó a ocho profesionales de Unidades de Salud de la Familia, una urbana y otra rural. Los datos se analizaron desde la perspectiva del análisis de contenido. Los resultados mostraron el miedo de algunos participantes en relación a las personas con trastornos mentales y un intento de los profesionales de reconocer a estas personas desde un punto de vista. En cuanto al manejo, se observaron procedimientos como la recolección de historia de vida, visitas domiciliarias y la dificultad de la familia para participar en el tratamiento. Finalmente, se identificó la necesidad de trabajar con equipos con conocimientos sobre trastornos mentales, vinculación y Atención Primaria.

Palabras clave: atención primaria de salud, trastornos mentales, equipos de salud familiar

\footnotetext{
${ }^{1}$ Endereço para contato: Rua Bororós, 30, Vila Togni, Poços de Caldas, Minas Gerais. Telefone: (35) 99811-8017. E-mail: csfilho@live.com
} 


\section{Introdução}

Este artigo explora como os profissionais de saúde da Atenção Básica, em um município de médio porte, lidam com pacientes com transtornos mentais severos e persistentes. Para compreender esse fenômeno no primeiro nível de assistência em saúde, buscou-se uma aproximação com o trabalho realizado pelos profissionais das Equipes de Saúde da Família (EqSF).

A Reforma Psiquiátrica brasileira tomou como eixo prioritário de trabalho o cuidado com a população com transtornos mentais severos e persistentes, os quais envolveriam as ". . - pessoas com grave comprometimento psíquico, incluindo os transtornos relacionados às substâncias psicoativas (álcool e outras drogas) e também crianças e adolescentes com transtornos mentais" (Brasil, 2004, p. 15). Essa parcela da população passou a ter outra possibilidade de tratamento, por intermédio de serviços substitutivos ao hospital psiquiátrico.

Para a atenção a esse contingente que apresenta transtornos mentais, surgiram serviços sob uma lógica de atenção no território, para manter o vínculo comunitário, sendo que esses vêm a compor a Rede de Atenção Psicossocial (RAPS). Integram esta rede o Centro de Atenção Psicossocial (CAPS), os Serviços Residenciais Terapêuticas (SRT) e as Unidades Básicas de Saúde (UBS) e Unidades de Saúde da Família (USF). O CAPS e o SRT são dispositivos provenientes da Reforma Psiquiátrica que se destinam exclusivamente à clientela de saúde mental, como serviços substitutivos às internações hospitalares (Vidal, Bandeira, \& Gontijo, 2008). Já as UBS e USF são dispositivos da Atenção Básica e destinam-se a cuidar do conjunto de habitantes de sua área adscrita, e não apenas das pessoas com transtornos mentais. Essas unidades viabilizam o atendimento na própria comunidade, residência e, por isso, são porta de entrada para os demais serviços da RAPS (Brasil, 2000).

Souza e Andrade (2014) afirmam que a noção de território na área da Saúde passou a ter mais importância em decorrência da descentralização, a partir do ano de 1990, momento em que o município assume maior responsabilidade sobre a saúde de seus moradores. Segundo Ferreira (2017) entre outros, o termo território não designa apenas o espaço geográfico, mas é portador de uma dinâmica singular que envolve processos sociais e de subjetivação. Assim, essa noção não indica apenas a proximidade do serviço com o local de residência do usuário, mas possui outra conotação referida aos modos de vida presentes naquele espaço.

Segundo Büchele, Laurindo, Borges e Coelho (2006), a USF seria uma alternativa para a saúde mental reorganizar a atenção psiquiátrica a partir da Atenção Básica em Saúde, como uma proposta de cuidado territorial e de encaminhamentos. Mesmo havendo encaminhamentos, os indivíduos continuam sendo da equipe, pelo tempo que esses residirem no mesmo bairro do serviço de saúde (Dantas \& Passos, 2018). Para tanto, suas ações são realizadas por uma equipe multidisciplinar, que é integrada por médico, enfermeiro, técnicos de enfermagem e agentes comunitários de saúde (ACS) (Brasil, 2012).

Neste estudo, foram selecionadas uma USF urbana e outra rural, nas quais estas equipes atuam com pessoas com transtornos mentais. A USF da zona urbana escolhida está localizada na região leste da cidade e é responsável por quatro bairros.

Conforme o Plano de Ação em Saúde da Zona Rural de 2018, a população da zona rural atendida pelas EqSF rurais é distribuída de acordo com as famílias atendidas pela unidade, sendo 564 famílias atendidas pelas equipes. A zona rural é dividida em seis microáreas, 
denominadas fazendas. Há variações da vulnerabilidade social entre essas fazendas, sendo uma delas um território com condições socioeconômicas mais frágeis e outra uma fazenda que gera mais empregos.

A Política Nacional de Saúde Integral das Populações do Campo e da Floresta foi desenvolvida para assegurar os direitos da população rural, tendo em vista as suas especificidades territoriais (Brasil, 2013). Tal política visa contemplar o contexto rural brasileiro que ". . . é resultado de sua história econômica, política e cultural fundada na concentração de terra, de riqueza, uso dos recursos naturais, escravidão, extermínio de povos indígenas, marginalização de famílias e mulheres camponesas ..." (Brasil, 2013, p. 9).

Estudos demonstram que a população rural está submetida à estigmatização e condição de marginalização, que podem afetar a saúde mental do indivíduo e, consequentemente, repercutir em sua perspectiva de vida, assim como seu fechamento em relação à sociedade (Costa \& Dimenstein, 2017). Esse ambiente também se caracteriza pela dificuldade de acesso à educação, favorecendo baixos graus de escolaridade, o que limita mais as possibilidades de inserção social dos moradores de regiões rurais, assim como a disponibilidade de serviços nessas localidades, como serviços de saúde fixos ou móveis; e, na ausência desses, essa população precisa se deslocar para a região urbana, como é observado no município pesquisado.

Portanto, este estudo buscou conhecer a atuação de profissionais da ESF junto às pessoas com transtornos mentais severos e persistentes. Para tanto, foram identificados os sentidos produzidos pelos membros de equipes de saúde em relação às pessoas com transtornos mentais severos e persistentes, usuárias de unidades da Atenção Básica. Além disso, visou-se descrever as práticas realizadas pelas equipes junto aos usuários com transtornos. Dessa forma, os sentidos produzidos pelos profissionais e o manejo do trabalho foram os dois eixos analíticos utilizados.

\section{Metodologia}

Trata-se de uma pesquisa qualitativa, por discutir uma problemática por meio da concepção dos indivíduos envolvidos. O estudo também é de cunho descritivo, pois busca descrever fenômenos da maneira como ocorreram e apareceram.

Os participantes desta pesquisa foram profissionais de duas Unidades de Saúde da Família (USF), sendo uma da zona urbana e outra da zona rural do município de Poços de Caldas, as quais foram selecionadas entre todas as unidades do município. Salienta-se que todos são efetivos na Secretaria Municipal de Saúde de Poços de Caldas por intermédio de concurso público.

A partir dos dados das equipes distribuídas no município, foram selecionados oito participantes, sendo um médico, um enfermeiro e dois agentes comunitários de saúde (ACS), provenientes de USF urbana; e um médico, um enfermeiro e dois ACS de USF rural. O critério de escolha dos profissionais selecionados foi trabalharem há mais tempo nas unidades. No que concerne à análise desses dois contextos, o estudo foi realizado mediante uma amostragem por contraste, de modo a viabilizar uma comparação, bem como apresentar uma totalidade diversa (Poupart, Deslauriers, Mayer, \& Groulx, 2014).

Os temas que nortearam as entrevistas realizadas com os participantes foram: contato inicial com a saúde mental; uma descrição de experiências com pessoas diagnosticadas com 
transtorno mental; os sentidos elencados às pessoas com transtorno mental severo e persistente; possíveis especificidades na clientela com transtorno mental severo e persistente que a distinguem do público geral; dificuldades para lidar com essas pessoas; a atuação profissional em relação às pessoas com transtorno mental severo e persistente; e os procedimentos realizados com a clientela de saúde mental. Desses temas, emergiram o material e as categorias, as quais compõem as experiências das EqSF com as pessoas com transtornos mentais severos e persistentes.

Quadro 1

Descrição dos participantes entrevistados das USF Urbana e USF Rural

\begin{tabular}{|c|c|c|c|c|c|c|c|}
\hline Unidade & Participantes & Abreviações & Idade & $\begin{array}{c}\text { Estado } \\
\text { civil }\end{array}$ & $\begin{array}{c}\text { Número } \\
\text { de filhos }\end{array}$ & Escolaridade & $\begin{array}{c}\text { Tempo de } \\
\text { serviço }\end{array}$ \\
\hline $\begin{array}{c}\text { USF } \\
\text { Urbana }\end{array}$ & Enfermeira & E1 & 34 & Casada & - & $\begin{array}{c}\text { Mestrado } \\
\text { completo }\end{array}$ & 10 anos \\
\hline $\begin{array}{c}\text { USF } \\
\text { Rural }\end{array}$ & Enfermeiro & E2 & 27 & Casado & - & $\begin{array}{c}\text { Pós-Graduação } \\
\text { completa }\end{array}$ & 2 anos \\
\hline $\begin{array}{c}\text { USF } \\
\text { Urbana }\end{array}$ & Médica & M1 & 27 & Solteira & 1 & $\begin{array}{c}\text { Graduação } \\
\text { completa }\end{array}$ & 3 anos \\
\hline $\begin{array}{c}\text { USF } \\
\text { Rural }\end{array}$ & Médico & M2 & 33 & Solteiro & - & $\begin{array}{c}\text { Pós-Graduação } \\
\text { completa }\end{array}$ & 5 anos \\
\hline $\begin{array}{c}\text { USF } \\
\text { Urbana }\end{array}$ & $\begin{array}{c}\text { Agente Comunitária } \\
\text { de Saúde 1 }\end{array}$ & ACS1 & 42 & Casada & 4 & $\begin{array}{c}\text { Ensino Médio } \\
\text { Completo }\end{array}$ & 12 anos \\
\hline $\begin{array}{c}\text { USF } \\
\text { Urbana }\end{array}$ & $\begin{array}{c}\text { Agente Comunitária } \\
\text { de Saúde 2 }\end{array}$ & ACS2 & 41 & Solteira & 2 & $\begin{array}{c}\text { Ensino Médio } \\
\text { Completo }\end{array}$ & 4 anos \\
\hline $\begin{array}{c}\text { USF } \\
\text { Rural }\end{array}$ & $\begin{array}{c}\text { Agente Comunitária } \\
\text { de Saúde 3 }\end{array}$ & ACS3 & 35 & Solteira & 1 & $\begin{array}{c}\text { Ensino Médio } \\
\text { Completo }\end{array}$ & 6 anos \\
\hline $\begin{array}{c}\text { USF } \\
\text { Rural }\end{array}$ & $\begin{array}{c}\text { Agente Comunitária } \\
\text { de Saúde 4 }\end{array}$ & ACS4 & 58 & Casada & 1 & $\begin{array}{c}\text { Ensino Médio } \\
\text { Completo }\end{array}$ & 25 anos \\
\hline
\end{tabular}

Fonte: Dados da pesquisa.

A Secretaria Municipal de Saúde e os participantes foram contatados para a anuência da pesquisa e realização em suas dependências. Realizamos entrevistas semiestruturadas com os participantes, gravadas e transcritas para posterior análise.

A análise de dados foi pautada pela análise de conteúdo com base na Metodologia ClínicoQualitativa que se atenta ao modo como o participante experiencia e atribui significação às suas interações (Turato, 2003). Decorrida a coleta de dados, realizou-se uma leitura flutuante como um primeiro modo de se acessar o conteúdo das narrativas. A partir de uma leitura exaustiva das transcrições, foi realizado o processo de construção de categorias. A construção de categorias decorreu dos elementos que mais se repetiram e que foram ao encontro com o problema de pesquisa.

Duas categorias emergiram da análise, os sentidos atribuídos pelos profissionais ao usuário da saúde mental e o manejo na atuação com pessoas com transtorno mental. Tais categorias representam o modo como a experiência da atuação das EqSF puderam se desvelar ao pesquisador, como representativas de percepções que perpassam a experiência e de ações destinadas a especificidades da clientela. Cada uma delas se desdobrou em outras 
subcategorias, sendo elas: o medo do contato com usuários da Saúde Mental; uma tentativa de dar sentido ao outro; procedimentos realizados com a clientela com transtorno mental; o distanciamento familiar e o vínculo com a unidade; e a compreensão sobre a complexidade da atenção.

A pesquisa foi aprovada pelo Comitê de Ética em Pesquisa envolvendo Seres Humanos da Pontifícia Universidade Católica de Minas Gerais, número do Parecer 2.485.822.

\section{Resultados e Discussão}

Sentidos atribuídos pelos profissionais ao usuário da Saúde Mental

A referida categoria vai ao encontro de um dos objetivos que trata dos sentidos atribuídos à clientela com transtornos mentais, e esses são ressaltados como alguns elementos presentes no contato das equipes de saúde com os usuários. Assim, ela visa conhecer algumas significações que foram construídas durante a formação dos profissionais e na sua experiência prática.

Um dos elementos presentes na percepção sobre a clientela referida por dois dos oito entrevistados foi o medo em lidar com a clientela de saúde mental. Nos depoimentos, há elementos de experiências traumáticas em atendimentos com pessoas com transtornos mentais, assim como um receio da equipe em sua atuação. Esse medo é associado à possibilidade de que o usuário, em momento de crise, reaja com agressividade com o profissional durante uma abordagem técnica, como pode ser observado a seguir:

... na minha percepção, né, como médica, como pessoa, a gente tende a ter o medo da pessoa. Ah, é esquizofrênico, ou tem até outros tipos de transtorno. Tipo a gente tem que, pensando na área da Atenção Básica, a gente sempre acolhe a pessoa e tenta fazer o melhor, né, tentar encaminhar para as áreas específicas. Mas são doenças que sempre causam medo nas outras pessoas, até quando a gente está atendendo paciente. Se tem um paciente em surto as outras pessoas ficam incomodadas, mas para mim é tudo a mesma coisa. A gente começa, a gente tem medo de ser agredida, que já aconteceu algumas vezes. ... Sim. Eu e os meus colegas (já foram agredidos). (M1).

Ah, sim, é na minha área não tem muito paciente assim com transtornos mentais, né, é. Mas eu fico até apreensiva, sim, quando chegar abordar sabe. (ACS1).

Nos relatos, é perceptível o medo associado ao indivíduo com transtorno mental severo e persistente, como algo que advém de uma construção subjetiva, tanto cultural quanto particular. Como construção social, o medo seria perpassado pela concepção de que o sujeito representaria algum perigo na relação com o outro (Amaral, Torrenté, Torrenté, \& Moreira, 2018; Maciel, Barros, Camino, \& Melo, 2011; Pegoraro et al., 2014). Isso é expresso no relato da médica, "Mas são doenças que sempre causam medo nas outras pessoas", como uma percepção socialmente constituída, ainda que alegue que no trato com os pacientes não faça diferença a partir do diagnóstico. Ao final, relata que ela e os colegas sofreram agressões, o que denota ambiguidade em sua postura.

De outra forma, existem concepções do sujeito com transtorno como um indivíduo que destoa em relação ao que Ihe é esperado no convívio social, sendo visto como estranho. Entretanto, esse medo também tem ligação com a relação estabelecida prioritariamente, a 
partir de uma medicalização predominante na atuação das EqSF, como prescrições de medicamentos e orientações em relação a eles, somente pautada em uma compreensão orgânica, como se tal fenômeno tivesse apenas que ser medicalizado e essa fosse a primeira e principal opção para o sujeito (Machado \& Pereira, 2013; Pegoraro et al., 2014). Aliás, assim como para tais profissionais, a medicação aparece como principal conduta, e esta é considerada da mesma forma pela população, conforme a pesquisa de Bispo e Moreira (2018), como sendo a primeira possibilidade que o serviço teria a oferecer.

Um segundo sentido na aproximação com o usuário identificado foi uma tentativa de dar significação ao outro, de lidar com o diferente, demarcando uma estranheza da parte do profissional. Em sete das entrevistas, os participantes, ao tentarem sinalizar a diferença das pessoas com transtornos mentais severos e persistentes da clientela geral, descreveram tais indivíduos como não sendo normais, e outros os percebiam como pessoas estranhas, o que pode ser observado nos relatos abaixo:

São pessoas que controladas, muitas delas conseguem dependendo do grau de capacidade lógico "tem", conseguem ter uma vida normal, né. (E1).

Essa fala sinaliza que o tratamento oferece ao indivíduo com transtornos mentais uma melhora na sua relação com a comunidade. Entretanto, traz a ideia de controle como se algo precisasse de ser feito em relação a alguém, uma intervenção externa para viabilizar o desenvolvimento de atividades comuns, diárias. De forma semelhante, vê-se a utilização de medicações e a aplicação de outras possibilidades terapêuticas como fatores que viabilizam o equilíbrio de um indivíduo (Borba et al., 2018). Assim, as terapêuticas são vistas como meios de atenuar sintomas, lidar com incapacidades e potencializar modos de se posicionar no mundo.

Então a pessoa que tem a doença mental, ela tem um sofrimento muito grande na parte social e é muito difícil tentar achar um equilíbrio a enfermidade, manter o controle da enfermidade e a pessoa ter uma vida normal. (E2).

Outro enfermeiro aponta a influência do meio social como gerador de dificuldades para o paciente. Há uma busca de equilíbrio no que se espera entre o profissional e o usuário, procurando um limiar no qual o indivíduo não seja visto pela enfermidade, o transtorno, ou seja, pelo sintoma, mas pelo modo como ele se reconhece na relação e consegue se envolver nela. Nesse aspecto, acredita-se que ocorreria uma mudança ou até cura com o tratamento.

O sentido de controle apresentado pelos enfermeiros pode ser observado a seguir: "São pessoas que controladas, muitas delas conseguem dependendo do grau de capacidade lógico tem, conseguem ter uma vida normal ..." (E1) e ". . . é muito difícil tentar achar um equilíbrio a enfermidade, manter o controle da enfermidade e a pessoa ter uma vida normal" (E2). Nestes, o controle aparece como algo necessário, para haver uma suposta normalidade, normalidade que requer uma medicação, um procedimento que provenha condições a esse sujeito de ter "uma vida normal". Esse normal que não é claramente definido e pode estar ligado apenas ao controle de sintomas e fortalecer uma compreensão de que o usuário deve ser tutelado em sua vida, como se fosse limitado para além de seu momento de crise (Machado \& Pereira, 2013). Uma concepção que desconsidera o sujeito como agente de mudanças e para além de uma condição psicopatológica. 
É uma das pacientes que eu ultimamente achei que estava muito surtada, mas ela não faz tratamento no CAPS, não faz tratamento em lugar nenhum, porque ela não quer aderir aos tratamentos. Ela fala que a vida dela é cuidar do filho, então ela não toma nenhum medicamento. E aí que a gente percebeu que agora não dá para ficar do jeito que está. Que antes ela era estranha, mas era uma estranha que passava meio que despercebida. ... Assim, elas destacam mais, né. Elas destacam mais, sim. A gente vê que tem um problema, né. (ACS2).

No relato da ACS2, o desequilíbrio está associado à ausência de tratamento, percebida pela falta de acompanhamento da usuária no CAPS e por ela não estar tomando medicação. O fato de a usuária não estar sendo assistida pelo CAPS é justificado pela não adesão desta, que é por sua própria vontade. E, quando aponta que não toma medicação, a participante estabelece uma relação da ausência do tratamento medicamentoso à ocorrência de um "surto", como em outras pesquisas (Borba et al., 2018). Além disso, a participante é chamada de estranha, e isto que aparenta ser o que causa incômodo, estranheza na percepção do outro, para a agente afirmar que a usuária não pode permanecer do jeito que está. Entretanto a estranheza não é aprofundada, sendo reconhecida a partir de um juízo moral.

Se distingue (pausa) sim, tem diferença. Que cada um age de uma forma, né. Quem tem problemas, a saúde mental afetada, eles agem de forma diferente do que outro que não, digamos assim que é normal, né (risos). (ACS1).

O físico já fala, eles geralmente têm uma aparência diferente, são mais agitados, é a vida social não é tão fácil, né .. . Muito parado, tem uns que ficam até com a boca aberta, é falam coisas repetitivas, geralmente, nos meus casos são assim. (ACS3).

Como indivíduos, aí como eu vou te responder é, assim eles não ficam muito, como se diz na sociedade, né, mais ou menos isso. Eles têm dificuldade infelizmente, porque não é todo mundo que aceita, tem muita gente que recrimina eles, então é uma situação bem complicada. (ACS4).

A percepção de que não seriam normais, ". . . eles agem de forma diferente do que outro que não, digamos assim que é normal" (ACS1), ou seja, há algo que é esperado pela agente e no modo como esta percebe o usuário não atribui sentido de que este seria normal, por este não ir ao encontro do que existe como expectativa. Essa tentativa de dar sentido também é proveniente de uma construção social, para a qual a loucura ou o transtorno mental estariam ligados à anormalidade, característica que aparta o sujeito de uma identidade coletiva (Cândido et al., 2012). Essa é uma construção social que interfere na participação social dos usuários, como é visto em um dos trechos de duas agentes: ". . . são mais agitados, é a vida social não é tão fácil, né" (ACS3) e ". . . não é todo mundo que aceita, tem muita gente que recrimina eles" (ACS4). Nesses discursos, destaca-se a percepção de um preconceito social em relação às pessoas com transtornos mentais, muitas vezes ligada a uma concepção de heteroagressividade ou de inadequação nos relacionamentos sociais (Maciel et al. 2011; Pegoraro et al., 2014). Por essa via, o preconceito promove um distanciamento, que é percebido na convivência comunitária do usuário.

Além disso, a expressão ser "estranho" e "destacar mais" em si mesmas não lançam luz sobre a problemática, porém são modos de se referir à outra pessoa que provoca 
estranhamento no contato entre duas subjetividades. Essa percepção ainda diz sobre uma construção a partir das interações que os participantes tiveram com esses indivíduos e de suas formações em relação à saúde mental. Aliás, esse significado de ser estranho relaciona-se a uma percepção social, que, por sua vez, pode estar associada ao medo de quem se mostra diferente nas relações cotidianas (Maciel et al., 2011). Essa estranheza pode estar ligada ao que a ACS3 relatou, de que os utentes com transtorno mental severo e persistentes ". . são mais agitados", o que se apresenta a ela como diferença e marca o indivíduo. Marca que deixa de ser um estado, para um modo de ser que afeta o outro, ainda acrescenta que também são ". . . muito parados, tem uns que ficam até com a boca aberta, é falam coisas repetitivas", sentidos esses que podem estar relacionados ao excesso de medicação para conter o que atribuem como estranheza que, por exemplo, seria a agitação intensa.

Os elementos do contato com o usuário foram vistos a partir do medo de contato e de uma tentativa de dar sentido ao outro. Esses aspectos presentes na relação com o utente dizem e se implicam no cuidado com a clientela, uma vez que é por meio de concepções que se desenvolvem as interações. Assim, é notável que, mesmo com uma experiência de alguns anos, duas entrevistadas demonstraram que ainda têm medo de pessoas com transtornos mentais severos e persistentes, fator que pode trazer implicações no cuidado em saúde para esta clientela. É perceptível também uma tentativa de atribuir significado ao modo de ser do indivíduo, entretanto, compreendem-no por intermédio de um ideário estigmatizado e inflexível. Como diferenças na concepção de ambas as USF, pode-se notar que apenas dois profissionais da USF urbana apresentaram algum receio em relação à clientela com transtornos mentais, enquanto os profissionais da USF rural não demonstraram a mesma preocupação. É perceptível que o usuário foi visto com sua problemática durante o tratamento, já na zona urbana ele foi percebido antes de uma problematização e oferecimento de cuidado. Ou seja, dois participantes perceberam o usuário de duas maneiras distintas, que demonstram um desafio para o seu trabalho: uma, o utente antes de aderir a um serviço de saúde; outra, a manutenção desse tratamento em relação à qualidade de vida do usuário. Em relação às ACS, notou-se que as agentes da USF urbana se ativeram à diferença pública (física) e orgânica do momento de crise da pessoa com transtornos mentais, já as agentes da USF rural partiram de uma perspectiva mais psicossocial, considerando que há um preconceito e como isto afeta a vida do usuário.

\section{Manejo na Atuação com Pessoas com Transtorno Mental}

Essa categoria se coaduna com o objetivo de descrever as ações desenvolvidas pelos participantes para as pessoas com transtornos mentais severos e persistentes. Consecutivamente, a compreensão dos profissionais sobre a clientela de saúde mental segue o seu modo de atuação, em seu manejo específico com esses usuários. Além das especificidades do usuário propriamente dito, existe uma conflitiva que ultrapassa a nosologia, trazendo dificuldades ao tratamento. Observa-se também a percepção das equipes sobre o desempenho de seu trabalho e os seus atravessamentos, visto que faz parte do que é oferecido pela RAPS, e essa percepção afeta o manejo em relação à destinação do usuário na rede de saúde.

Quanto ao manejo realizado pelos profissionais da unidade, foram elencados alguns procedimentos desenvolvidos com a clientela de saúde mental. Dessa forma, tais propostas 
visam compreender a problemática da demanda e construir estratégias de cuidado, tal como será apresentado:

A gente sempre faz uma primeira consulta, né .. uma anamnese completa pra gente, a gente não diagnostica na primeira vez, a gente vai fazendo todo um acompanhamento de uns 3 a 6 meses, pra poder ter alguma noção do diagnóstico que não pode fazer de primeiro. (M1).

Então, assim, em primeiro momento é tentar diagnosticar o mais rápido possivel e tentar. Eu já começo tratando, entendeu. Alguns casos, o severo a gente não consegue porque a demanda que a gente tem é muito grande... Em um primeiro momento a gente tenta tratar, já começa a medicação e orienta a família. (M2).

No discurso dos médicos, nota-se uma diferença. A médica tem um cuidado em diagnosticar, para uma maior precisão e tratamento, como se pode observar na fala a seguir: "A gente não diagnostica na primeira vez, a gente vai fazendo todo um acompanhamento de uns 3 a 6 meses, pra poder ter alguma noção do diagnóstico que não pode fazer de primeiro". Já o médico acredita que "Em primeiro momento é tentar diagnosticar o mais rápido possível" e demonstra uma preocupação imediata para iniciar o tratamento, como afirma: "Eu já começo tratando". Todavia essa rapidez no diagnóstico pode culminar em uma imprecisão e, consequentemente, em um equívoco no manejo do cuidado, como, por exemplo, na prescrição de medicações que não sejam efetivas para a singularidade que for apresentada e vivida pelo usuário. Além disso, essa preocupação sinaliza uma dificuldade em lidar com um desconhecimento sobre o sujeito, que pode ser conhecido a partir de mais tempo de contato durante um acompanhamento por um maior período até uma percepção acerca de uma hipótese diagnóstica. $\mathrm{O}$ ato de ouvir e coletar a história de vida está presente na maioria das entrevistas. Em outras pesquisas, aparecem como parte das atividades da EqSF, também, consultas, encaminhamentos, orientações e entrega de medicações (Baralhas \& Pereira, 2010).

Nos relatos dos demais participantes, é prevalente a utilização de um procedimento comum tanto no discurso dos enfermeiros como no das agentes comunitárias de saúde, que foi a visita domiciliar. A visita domiciliar seria uma das maneiras de atuação mais prevalentes no fazer cotidiano, mas pode acontecer com diferentes propostas e objetivos, como se pode observar:

Olha, a gente ... conversa com a família, tenta apoiar a família, ... conversa com o paciente, tenta adquirir aquele vínculo com ele. Então a nossa atuação é direta nas visitas domiciliares... (E2).

Na perspectiva do enfermeiro, ele tenta dar suporte à família, aproximar-se dela, para o desenvolvimento de sua atuação. Da mesma maneira, acessando este ambiente familiar, busca-se acessar o indivíduo que apresenta demanda para a Atenção Básica. A visita domiciliar passa a ser um dos meios de ir ao encontro do usuário e compreender o seu contexto, como uma tentativa de vinculação, de ser uma referência de atenção em saúde para o sujeito (Andrade \& Cardoso, 2017). Segundo o Conselho Federal de Psicologia (2013), a construção do vínculo acontece desde o primeiro contato do profissional com o indivíduo e está relacionada à maneira como ele é tratado incialmente. E esse vínculo seria uma forma de responsabilidade compartilhada que é desenvolvida e diz respeito também ao cuidado de 
si, de uma atenção em saúde. E, como em seu relato, esse é um procedimento fundamental na unidade rural, por meio do qual estabelecem contato com os usuários que residem até alguns quilômetros de distância da unidade USF. Nesse aspecto, o vínculo seria um modo de oferecer o serviço de saúde, de sistematizar um cuidado e de corresponsabilizar o indivíduo por seu autocuidado.

Visito sempre mais eles que o outro pessoal. ... Então, como eles chegam, eles têm sempre, mesmo que não tem mais vaga com a médica, a gente encaixa eles, para passar na nossa médica. (ACS2).

A agente comunitária estabelece uma diferenciação quando expressa que visita as pessoas com transtornos mentais severos e persistentes mais que "o outro pessoal", ou seja, as pessoas que não têm transtornos mentais. A agente demonstra uma necessidade maior em atender à demanda desses usuários da USF, pois, quando detectam a necessidade nestes indivíduos, os profissionais da unidade fazem um encaixe com a médica clínica geral. Mesmo esses não compondo as estratégias programáticas da Atenção Básica, como a realização da puericultura, acompanhamento do pré-natal, um controle da hipertensão arterial, da diabetes mellitus, eliminação da tuberculose, prevenção ao câncer de colo uterino, estímulo ao aleitamento materno, a eliminação da hanseníase, assim como enfoque na saúde infantil, da mulher, do idoso e da saúde bucal (Brasil, 2006; Pinto, Sampaio, Lobo, Maciel \& Jorge, 2016). Segundo Bones Rocha et al. (2017), o procedimento de visitas domiciliares tem por objetivo atingir os utentes e as famílias, como um acompanhamento que considera a individualidade do usuário, é uma forma de assistir a pessoa, pode ter cunho educativo e ser uma maneira de integrar a família na assistência em saúde de seu ente familiar. Então esse acompanhamento para a população com transtornos mentais se apresenta como uma ação para sistematizar o cuidado.

Orientação, né. A gente orienta, a gente. É orientação e fica em cima também, não deixa acabar os medicamentos, se não aí, se tiver que voltar no médico 6 meses por exemplo, às vezes eles dão uma receita que vale por 6 meses, durante esses 6 meses a gente não deixa eles ficarem sem remédio, "tá" (sic) sempre atento pra pegar receita e acompanhando sempre. A gente não desiste nunca, né. (ACS4).

Por fim, a ACS4 realiza a visita domiciliar com um objetivo mais operacional/técnico, para orientar - orientação que pode ser feita à família ou ao usuário, no sentido de uma explicação sobre a psicopatologia e a administração da medicação, a fim de orientar a família ou utente a buscar a medicação e renovar a receita para que este último não fique sem o medicamento. Essas orientações a partir da visita domiciliar acontecem como um modo de corresponsabilizar o sujeito sobre o seu tratamento. Vale ressaltar que tal prática de visita domiciliar é correntemente utilizada por diversas pesquisas na atuação das EqSF (Andrade \& Cardoso, 2017; Baralhas \& Pereira, 2010). Ela ocorre com o objetivo de conhecer, orientar, informar e acompanhar tanto o usuário de saúde mental quanto a sua família.

Já a ACS2 aponta que "Visito sempre mais eles que os outro pessoal", o que pode estar relacionado à crença de que tais usuários teriam menor adesão à unidade, até mesmo pela falta de vinculação com a EqSF, ou a falta de ação dos próprios profissionais na construção desse vínculo (Cardoso \& Galera, 2009). E, por acreditar na dificuldade na adesão ao 
tratamento que é predominantemente medicamentoso nas unidades, há uma preocupação, como referido pela ACS4: ". . fica encima também, não deixa acabar os medicamentos, se não aí, se tiver que voltar no médico 6 meses, por exemplo". Além disso, as visitas são uma possibilidade de acompanhar a evolução do indivíduo e, havendo alterações nessa evolução, podem ser propostas consultas médicas.

Quando os entrevistados foram arguidos se tinham dificuldades em lidar com as pessoas com transtornos mentais severos e persistentes, a maioria afirmou não ter dificuldades no cuidado, sendo eles as agentes comunitárias de ambas as unidades e o enfermeiro da USF rural. Já alguns participantes da USF urbana apresentaram maior dificuldade em ter a família do usuário como apoiadora do tratamento, o que pode estar associado ao fato de a visita domiciliar ser vista como uma forma de o utente se aproximar da família, o que não foi observado nas entrevistas da EqSF urbana. No entanto, os demais profissionais relataram não ter dificuldade com o indivíduo com transtorno, mas com sua família.

... o que eu mais vejo assim, de dificuldade, é, eu acho que é a família, ainda tem algumas dificuldades, assim, auxiliar no medicamento, em evitar que os surtos aconteçam. Então esse é o nosso maior desafio, né. Muitas e muitas vezes, a gente já organizou medicamento para paciente vir até aqui tomar, por conta da família não oferecer este medicamento. (E1).

A enfermeira da região urbana percebe uma dificuldade da família em colaborar com o tratamento, como na administração da medicação, para evitar que os sintomas de um momento de crise venham a emergir. Em função dessa dificuldade, é proposto ao usuário que tome, na unidade, a medicação, a qual passará a ser administrada pelo corpo de profissionais da enfermagem. Segundo Borba et al. (2018), a participação familiar foi observada como fator fundamental na adesão ao tratamento e ao uso de medicação por parte do usuário. Ou seja, o uso da medicação esteve relacionado com a adesão ao tratamento, visto que este tem uma função de lidar com questões orgânicas provenientes do transtorno. Em contrapartida, quando não há uma integração da família na atenção em saúde, as possibilidades de manejo diante da problemática do indivíduo ficam muito restritas, muitas vezes, a apenas ações da unidade, como o gerenciamento cotidiano da medicação do utente por parte dela.

Até, às vezes, é a família que nunca diagnosticou este tipo de pessoa, então ela deixa a pessoa vir sozinha e a gente tem dificuldade para colher a história, dificuldade para saber os tipos de medicamentos. (M1).

A concepção da médica assemelha-se à da enfermeira, apresentando uma dificuldade em lidar com a família do indivíduo com transtorno mental, pelo fato de, muitas vezes, essa não acompanhar o tratamento. No entanto, há uma ênfase do ponto de vista médico, sobre o diagnóstico, ou uma identificação e compreensão da condição do ente familiar com transtorno. Borba et al. (2018) notam que as pessoas que deixaram de tomar os medicamentos e as que não tinham o apoio familiar no tratamento tinham menor índice de adesão ao serviço de saúde. O uso de medicação e a participação da família são tidos como fundamentais para a adesão ao tratamento. A proximidade da família com a unidade de saúde é vista como uma maneira de ter mais acesso à história de vida do sujeito, à medicação utilizada, bem como pode funcionar como fator que venha a motivar o engajamento do usuário com a terapêutica. 
Muitas vezes o lado familiar é o que pega mais, vem casos assim, igual eu trabalhei em hospital psiquiátrico, o paciente estava estável, saía, voltava, porque a família não queria dar remédio, não entendia que o paciente tinha uma doença, achava que era fingimento e tudo mais. Então o mais difícil para nós de PSF é porque a gente tem que abordar toda a família, no consultório às vezes o psiquiatra, o especialista no CAPS vê o paciente, medica e pronto. (M2)

O médico da USF rural também percebe uma dificuldade no apoio da família ao indivíduo com transtorno mental, como não administrar a medicação e não compreender a patologia. De forma semelhante, a dificuldade em construir o vínculo entre o profissional com o usuário e sua família, pode estar ligada ao desconhecimento, bem como a concepções do senso comum que desacreditam de manifestações patológicas de ordem psicossocial (Dias, 2011; Rosa \& Labate, 2003). Entretanto, o médico parte de uma relação pontual de consultório para desenvolver sua percepção em uma estratégia que prima por contemplar toda a família. Vale ressaltar que ainda há na medicina uma prevalência do modelo biomédico, que tem enfoque no atendimento hospitalar e que, por sua vez, deixa de lado ". . aspectos psicossociais e comunitários" (Pereira \& Andrade, 2018, p. 6), o que é observado no relato do participante. E nesse aspecto há uma desconsideração de orientações e de uma abordagem familiar mais próxima desse contexto e que parta do conhecimento e da abertura da família para entender o que se mostra como patologia e o que é o sujeito.

Dessa maneira, é notória a demanda para que a família colabore com o tratamento proposto pelo serviço, visto que é ela que se encontra mais próxima da pessoa com transtorno mental e, muitas vezes, esta demanda um cuidado mais sistemático, que ultrapassa o realizado em instituições ambulatoriais. Assim, uma das barreiras que a equipe ainda precisa enfrentar é sair do modelo clínico e pontual de atendimento, para uma compreensão mais contextual do sujeito, a partir de sua família, sendo que este é um dos elementos que circundam o usuário. Segundo Ferreira (2017), há uma necessidade em considerar a família e a integração com sua comunidade, como também um modo de fazer sob uma perspectiva clínica que compreenda e interaja com os elementos sociais e que dão contorno à subjetividade do usuário. A relevância de aproximar a família da comunidade tem como objetivo potencializar o andamento do tratamento. No entanto, pode haver uma crença de despreparo tanto de atuações anteriores como de aporte teórico para o desenvolvimento de trabalhos com o grupo familiar, como os participantes de outro estudo (Ferreira, 2017). A falta de auxílio do grupo familiar ainda pode estar relacionada ao desconhecimento da condição do ente com transtorno mental, desconsiderando até a psicopatologia (Dias, 2011). Por outro lado, poderia haver um enfoque maior na atuação junto à família, como uma tentativa de lidar com esta dificuldade de alguns profissionais.

Identificou-se, na fala de uma profissional, uma dificuldade de compreensão acerca da complexidade da atenção em saúde no nível básico de um dos participantes. A Atenção Básica é tida pela médica como uma atuação mais fácil por ocorrer no nível básico de assistência, como se pode identificar a seguir:

Mas assim, é (pausa) eu prefiro mais trabalhar na Atenção Básica, né, enquanto não tem especialização, pela facilidade e pelo contato que você tem, né, com a população. (M1). 
Essa percepção é reforçada pela crença de que o médico generalista teria menos assertividade em relação às problemáticas apontadas. Assim, esse discurso desvaloriza a própria ação do profissional e deixa de lado a sistemática do cuidado e a capacidade de resolutividade na Atenção Básica. Vale salientar que o termo Atenção Básica foi adotado no Brasil, em vez de Atenção Primária de uso internacional, devido a este último estar ligado a algo primário, que seria destinado apenas para populações de baixo poder aquisitivo (Oliveira \& Pereira, 2013). Diferentemente, no Brasil, é adotado o termo Atenção Básica, pois essa assistência em saúde não é apenas um direito básico à saúde para uma parcela dos cidadãos, mas para toda a população, sendo um direito de todos. Nesse aspecto, mesmo em correlação com outros níveis de assistência por intermédio do matriciamento, há uma supervalorização das maiores complexidades em prol da básica.

Como manejo na atuação com as pessoas com transtornos mentais severos e persistentes, puderam se identificar alguns fatores, como: os procedimentos realizados; uma dificuldade em relação a lidar com a família do utente; e uma percepção sobre a complexidade do trabalho desenvolvido. Os procedimentos realizados eram a consulta, anamnese, diagnóstico, as vistas domiciliares e orientações, havendo mais destaque nos relatos nas avaliações e nas visitas. Vale ressaltar que houve diferenças na concepção da sistemática do diagnóstico, sendo que um médico prefere realizar o diagnóstico imediato, já a médica acredita ser necessário um tempo maior de avaliação para diagnosticar. Quanto às visitas, estas foram vistas como uma forma de ter maior contato com o usuário e assistir às famílias. Há uma percepção que descaracteriza a complexidade da Atenção Básica, apontando que nela não seriam tratadas as pessoas com transtornos mentais severos e persistentes e que seria espaço de problemáticas mais simples, associada a condução dos casos ao encaminhamento para as especialidades em saúde. Em suma, pode-se perceber uma diferenciação entre as duas EqSF, pois a maior parte dos participantes da USF urbana apontou dificuldades em lidar com a família da pessoa com transtorno mental em relação à USF rural. Nesse aspecto, apenas um participante da unidade rural reconheceu a importância da construção do vínculo na atuação da equipe em relação ao utente. Ou seja, existe uma preocupação maior, pelo menos em nível discursivo, com a vinculação do utente para a USF rural, o que também pode estar relacionado às suas dificuldades e ao seu manejo.

\section{Considerações Finais}

A partir dos resultados obtidos, pode-se considerar que esta pesquisa foi ao encontro dos objetivos e viabilizou conhecer a atuação de Equipes de Saúde da Família com as pessoas com transtornos mentais severos e persistentes. Dessa atuação, emergiram elementos presentes na relação estabelecida das equipes com os usuários, a identificação sobre o manejo - incluindo procedimentos -, as psicopatologias, as dificuldades e sua percepção sobre a Atenção Básica com RAPS, em termos de complexidade da Atenção.

Os elementos identificados da experiência dialogam com a proposta de compreender os sentidos atribuídos às pessoas com transtornos mentais severos e persistentes. Tais sentidos podem ser observados por intermédio do medo de contato, acompanhado de um esforço de dar sentido à pessoa com transtorno mental, tendo se correlacionado com a literatura e apresentado várias percepções distintas sobre os usuários, inclusive sobre profissionais da 
mesma equipe. Esses elementos apresentaram o modo como os profissionais percebem as pessoas com transtornos mentais severos e persistentes e como esses sentidos se constituíram por meio de sua formação profissional e experiências. E, a partir desses elementos, pôde-se entender como são desenvolvidos os manejos presentes na atuação cotidiana dos profissionais.

O manejo que diz da atuação prática diária com os indivíduos com transtornos mentais pôde ser identificado nas entrevistas. Nesse sentido, os manejos dos profissionais viabilizaram ir ao encontro do objetivo de descrever as ações desenvolvidas em relação às pessoas com transtornos. A partir de tal descrição, encontraram-se procedimentos comuns, mas diferenças entre as avaliações médicas, uma mais rápida com foco no diagnóstico e outra mais sistematizada, demandando maior período. Foi comum a utilização da visita, porém ressaltado um endereçamento tanto para o usuário quanto para a família e objetivos diferentes nessa abordagem em domicílio. Há uma variedade das demandas que estão relacionadas à diferença entre os territórios dos distintos usuários. Dessa diversidade, emergiu uma dificuldade de alguns participantes em lidar com a família do utente de saúde mental, a qual pode ser compreendida como um desafio para a formação do vínculo. Aliás, as experiências de manejo demonstraram como a problemática perpassa a prática dos trabalhadores da USF, como, por exemplo, na priorização do agendamento do atendimento médico, bem como nas visitas, que ocorrem com maior frequência. Além disso, uma percepção que acompanha o manejo foi o modo como os dois médicos sinalizam ver a atuação na Atenção Básica e sua repercussão para os indivíduos diagnosticados com transtornos mentais severos e persistentes, sendo que, para alguns, a USF não era o seu lugar.

O medo das pessoas com transtornos mentais e a tentativa de dar sentido ao outro podem ser abordados em grupos de discussões com os profissionais da saúde, dirigidos pelas equipes que realizam o matriciamento (Bispo, \& Moreira, 2018). Outra estratégia possível são as capacitações e demais cursos que venham tratar da temática de transtornos mentais, assim como do diagnóstico para se refletir sobre a Atenção Básica em meio a esta problemática e a complexidade de atenção (Pegoraro, Cassimiro, \& Leitão 2014). Ainda, pode-se discutir nos grupos algumas maneiras de buscar a aproximação da família junto ao tratamento do utente.

Portanto, pode-se compreender que este estudo viabilizou conhecer a prática de profissionais da USF que atuam com pessoas com transtornos mentais severos e persistentes. Entretanto, existem limitações no que tange à abrangência dessa proposta, como a quantidade de participantes e a coleta ser apenas realizada mediante entrevistas. Desta feita, são necessários estudos posteriores, que acompanhem a prática dos profissionais quando em contato direto com o utente, como nas visitas domiciliares, por exemplo, assim como colete a perspectiva de outros profissionais, como técnicos de enfermagem, com a finalidade de ampliar o escopo desta discussão.

\section{Referências}

Amaral, C. E. M., Torrenté, M. O. N. de, Torrenté, M. de, \& Moreira, C. P. (2018). Apoio matricial em Saúde Mental na atenção básica: Efeitos na compreensão e manejo por parte de agentes comunitários de saúde. Interface - Comunicação, Saúde, Educação, 22(66), 801-812. doi:https://dx.doi.org/10.1590/1807-57622017.0473 
Andrade, V. M. P., \& Cardoso, C. L. (2017). Visitas Domiciliares de Agentes Comunitários de Saúde: Concepções de Profissionais e Usuários. Psico-USF, 22(1), 87-98. doi:https:// dx.doi.org/10.1590/1413-82712017220108

Baralhas, M., \& Pereira, M. A. O. (2011). Concepções dos agentes comunitários de saúde sobre suas práticas assistenciais. Physis: Revista de Saúde Coletiva, 21(1), 31-46. doi:https:// dx.doi.org/10.1590/S0103-73312011000100003

Bispo, J. P., Júnior, \& Moreira, D. C. (2018). Núcleos de Apoio à Saúde da Família: Concepções, implicações e desafios para o apoio matricial. Trabalho, Educação e Saúde, 16(2), 683702. doi:https://dx.doi.org/10.1590/1981-7746-sol00122

Bones Rocha, K., Conz, J., Barcinski, M., Paiva, D., \& Pizzinato, A. (2017). A visita domiciliar no contexto da saúde: uma revisão de literatura. Psicologia, Saúde e Doenças, 18(1),170185. Recuperado de https://www.redalyc.org/articulo.oa?id=36250481015

Borba, L. O. de, Maftum, M. A., Vayego, S. A., Mantovani, M. F. de, Felix, J. V. C., \& Kalinke, L. P. (2018). Adesão do portador de transtorno mental à terapêutica medicamentosa no tratamento em saúde mental. Revista da Escola de Enfermagem da USP, 52(1), e03341. doi:https://dx.doi.org/10.1590/s1980-220x2017006603341

Brasil. (2000). A Implementação da Unidade de Saúde da Família. Brasília, DF: Ministério da Saúde.

Brasil. (2004). Ministério da Saúde. Saúde mental no SUS: Os centros de atenção psicossocial. Brasília, DF: Ministério da Saúde.

Brasil. (2006). Política nacional de atenção básica. Brasília, DF: Ministério da Saúde.

Brasil. (2012). Política Nacional de Atenção Básica. Brasília, DF: Ministério da Saúde.

Brasil. (2013). Política Nacional de Saúde Integral das Populações do Campo e da Floresta. Brasília, DF: Ministério da Saúde.

Büchele, F., Laurindo, D. L. P., Borges, V. F., \& Coelho, E. B. S. (2006). A interface da saúde mental na Atenção Básica. Cogitare Enfermagem, 11(3), 226-233, 2006. Recuperado de http://revistas.ufpr.br/cogitare/article/view/7308

Cardoso, L., \& Galera, S. A. F. (2009). Doentes mentais e seu perfil de adesão ao tratamento psicofarmacológico. Revista da Escola de Enfermagem da USP, 43(1), 161-167. doi:https:// dx.doi.org/10.1590/S0080-62342009000100021

Cândido, M. R., Oliveira, E. A. R., Monteiro, C. F. S. de, Costa, J. R. da, Benício, G. S. R., \& Costa, F. L. L. da (2012). Conceitos e preconceitos sobre transtornos mentais: Um debate necessário. SMAD-Revistaeletrônicasaúdementalálcooledrogas, 8(3),110-117. Recuperadodehttp:// pepsic.bvsalud.org/scielo.php?script=sci_arttext\&pid=S1806-69762012000300002\&Ing $=p t \& t \operatorname{lng}=p t$

Conselho Federal de Psicologia (2013). Referências Técnicas para Atuação de Psicólogas(os) no CAPS - Centro de Atenção Psicossocial. Brasília, DF: CFP.

Costa, M. C., Neto, \& Dimenstein, M. (2017). Cuidado psicossocial em saúde mental em contextos rurais. Temas em Psicologia, 25(4), 1653-1664. doi:https://dx.doi.org/10.9788/ TP2017.4-09Pt

Dantas, N. F., \& Passos, I. C. F. (2018). Apoio matricial em saúde mental no SUS de Belo Horizonte: Perspectiva dos trabalhadores. Trabalho, Educação e Saúde, 16(1), 201-220. doi:https://dx.doi.org/10.1590/1981-7746-sol00097 
Dias, M. K. (2011). A experiência social da psicose no contexto de um Centro de Atenção Psicossocial. Ciência \& Saúde Coletiva, 16(4), 2155-2164. doi:https://dx.doi.org/10.1590/ S1413-81232011000400015

Ferreira, J. L., Neto (2017). Psicologia, políticas públicas e o SUS (2a ed., rev. e ampl.). São Paulo: Escuta; Belo Horizonte: FAPEMIG.

Machado, M. P., \& Pereira, M. A. O. (2013). Percepção da doença mental por profissionais de saúde: Possibilidades de ampliação do cuidado. Estudos e Pesquisas em Psicologia, 13(1), 125-138. Recuperado de http://www.revispsi.uerj.br/v13n1/artigos/pdf/v13n1a08.pdf

Maciel, S. C., Barros, D. R., Camino, L. F, \& Melo, J. R. F. de (2011). Representações sociais de familiares acerca da loucura e do hospital psiquiátrico. Temas em Psicologia, 19(1), 193-204. Recuperado de http://pepsic.bvsalud.org/scielo. php?script=sci_arttext\&pid=S1413-389X2011000100015\&Ing=pt\&t|ng=pt

Oliveira, M. A. C. de, \& Pereira, I. C. (2013). Atributos essenciais da Atenção Primária e a Estratégia Saúde da Família. Revista Brasileira de Enfermagem, 66(Número Especial), 158164. doi:https://dx.doi.org/10.1590/S0034-71672013000700020

Pegoraro, R. F., Cassimiro, T. J. L., \& Leão, N. C. (2014). Matriciamento em saúde mental segundo profissionais da Estratégia da Saúde da Família. Psicologia em Estudo, 19(4), 621 631. doi:https://dx.doi.org/10.1590/1413-73722348905

Pereira, A. A. de, \& Andrade, D. C. L. (2017). Estratégia Educacional em Saúde Mental para Médicos da Atenção Básica. Revista Brasileira de Educação Médica, 41(4), 478-486. doi:https://dx.doi.org/10.1590/1981-52712015v41n4rb20160021

Pinto, A. G. A., Sampaio, K. R., Lôbo, A. C., Maciel, B. D., \& Jorge, M. S. B. (2018). Grupos prioritários da estratégia saúde da família: A atenção primária à saúde na prática. Journal of Nursing and Health, 6(3), 366-78.

Poços de Caldas (2018). Plano de Ação - Zona Rural 2018. Poços de Caldas, Minas Gerais: Secretaria Municipal de Saúde.

Poupart, J., Deslauriers, J., Mayer, J. V., \& Groulx, L. H. (2014). A pesquisa qualitativa: Enfoques epistemológicos e metodológicos (4a ed.). (A. C. Nasser, Trad.). Petrópolis: Vozes.

Rosa, W. de A. G., \& Labate, R. C. (2003). A contribuição da saúde mental para o desenvolvimento do PSF. Revista Brasileira de Enfermagem, 56(3), 230-235. doi:https://dx.doi.org/10.1590/ S0034-71672003000300004

Souza, C. L., \& Andrade, C. S. (2014). Saúde, meio ambiente e território: Uma discussão necessária na formação em saúde. Ciência \& Saúde Coletiva, 19(10), 4113-4122. doi:https://dx.doi.org/10.1590/1413-812320141910.08992014

Turato, E. R. (2003). Tratado de metodologia da pesquisa clínico qualitativa: Construção teórico-epistemológica, discussão comparada e aplicação nas áreas da saúde e humanas. Petrópolis: Vozes.

Vidal, C. E. L., Bandeira, M., \& Gontijo, E. D. (2008). Reforma psiquiátrica e serviços residenciais terapêuticos. Jornal Brasileiro de Psiquiatria, 57(1), 70-79. doi:https://dx.doi. org/10.1590/S0047-20852008000100013

\section{Sobre os autores:}

Carlos de Sousa Filho: Mestre em Psicologia pela Pontifícia Universidade Católica de Minas Gerais (PUC Minas). Graduado em Psicologia pela PUC Minas. Professor do curso de Graduação em 
Psicologia da Faculdade de São Lourenço (UNISEPE). E-mail: csfilho@live.com, Orcid: http://orcid. org/0000-0001-9075-3273

João Leite Ferreira Neto: Pós-doutor em Psicologia Social pela Universidade do Estado do Rio de Janeiro (UERJ). Doutor em Psicologia Clínica pela Pontifícia Universidade Católica de São Paulo (PUC-SP). Mestre em Filosofia pela Universidade Federal de Minas Gerais (UFMG). Graduado em Psicologia pela UFMG. Atua como professor adjunto no Departamento de Psicologia da Pontifícia Universidade Católica de Minas Gerais (PUC Minas), Programa de Pós-Graduação em Psicologia, Belo Horizonte, MG. Bolsista de produtividade do CNPq. E-mail: jleitefn@gmail.com, Orcid: http://orcid. org/0000-0003-3900-508X

Recebido em: 02/09/2019

Última revisão: 15/05/2020

Aceite final: 29/06/2020 
